\title{
Artistic Freedom or the Hamper of Equality? Exploring Ethical Dilemmas in the Use of Artistic Freedom in a Cultural Organization in Sweden
}

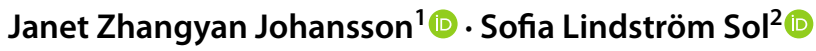

Received: 9 July 2020 / Accepted: 31 March 2021 / Published online: 21 April 2021

(c) The Author(s) 2021

\begin{abstract}
With this paper, from the perspective of ethics at the workplace, we problematize the taken-for-granted assumptions embedded in the use of artistic freedom in creative processes. Drawing on the notion of inequality regimes (e.g. Acker, 2006) and using empirical material from a performing arts organization in Sweden, we explore how the assumptions of artistic freedom facilitate and legitimize the emergence of inequality regimes in invisible and subtle manners. Our findings indicate that nonreflexive interpretations of the concept of artistic freedom result in ethical dilemmas that impact the organization's pursuits of equality work. The aesthetic ethics oriented around the notion of 'art for the sake of art' tends to camouflage the centralization of aesthetic authority in processes where formal hierarchical structures are missing. Consequently, asymmetrical power relations between the Directors, actors, and producers are legitimized. Ethics of quality of art and that of the social ideal of equality have been constructed as dichotomic notions indicating that aesthetic ethics of art can only be preserved at the expense of social objectives of equality. We argue that the current interpretative practices of 'artistic freedom' in some cultural organizations add little value of ethics to the freedom of expressing artistic opinions and in achieving the social ideal of equality but lead to the emergence of inequality regimes in the artistic work processes.
\end{abstract}

Keywords Inequality regime $\cdot$ Artistic freedom $\cdot$ Aesthetic authority $\cdot$ Equality $\cdot$ Diversity and inclusion

\section{Introduction}

Work organizations are critical locations for the investigation of complex societal inequalities (Acker, 2006). While there is a growing trend of implementing the paradigm of diversity management in various types of organizations, scholars within Critical Diversity Studies broadly question the ethical and political assumptions and unexpected consequences of these assumptions in the mainstream diversity management interventions (Pullen \& Rhodes, 2015; Tatli \& Özbilgin, 2012; Zanoni \& Janssens, 2007). Scholars call

Janet Zhangyan Johansson

janet.johansson@liu.se; jjzhang73@gmail.com

Sofia Lindström Sol

sofia.lindstrom@hb.se

1 Department of Management and Engineering, Linköping University, 58183 Linköping, Sweden

2 The Swedish School of Library and Information Science, University of Borås, 50190 Borås, Sweden for continuous efforts to scrutinize the ethicality of seemingly well-intended managerial initiatives in the pursuits of equality, diversity, and inclusion at work (Ahmed, 2007). With the case of a public-funded cultural organization in Sweden, this article explores ethical issues relating to the taken-for-granted assumptions embedded in the notion of artistic freedom and investigates its relevance to the emergence of inequality regimes in the art world. Inequality in this context refers not only to unequal opportunities and conditions in the artistic and creative processes with regard to race, gender, sexuality, and age but is also about the formation of disparities in terms of control over resources, goals, outcomes, and recruitment processes, as well as the wage, salaries, and other monetary incentives (Acker, 2006, 2009).

As a crucial aspect of ethics at workplaces, the subject of equality, diversity, and inclusion has gained growing attention in performing arts, particularly since the \#MeToo movement in 2017 (Lund, 2019). Taking the momentum of the \#MeToo movement, many organizations within the culture and art industry formulated formal policies and strategies and carried out actions to address issues around equality, 
diversity, and inclusion. However, scholars have discovered persistent systemic discrimination upon gender, race, and class in the art world and the creative/cultural industries, disrupting the state of equality in the film and creative sector (Eikhof \& Warhurst, 2013; Robinson, 2007). In Sweden, artists with non-Swedish backgrounds are significantly underrepresented in theatre and music; and their mean income is lower than that of artists with a Swedish background (Konstnärsnämnden, 2016). There remains an imbalance of ratio between men and women represented in managerial positions in cultural organizations, although the number of women has increased between 2001 and 2012 (Myndigheten för Kulturanalys, $2015^{1}$ ). Therefore, the \#MeToo movement is presumably the result of the systematic gender discriminations (SOU 2006: 42) due to the asymmetrical power distribution embedded in the artistic processes (Robinson, 2007).

When discussing ethics issues, one cannot overlook the fact that ethics in the arts have historically been related to moralism as censorship. The overall aesthetic quality of the artistic production or exhibition has long been the only ethical value deemed important (Belfiore \& Bennett, 2007; Haskins, 1989). The principle of artistic freedom/ autonomy, rooting deeply in the Kantian notion of 'art for the sake of art', has been a fundamental value shared by artists and cultural workers as a fair and just way to maintain desired aesthetic quality in artistic creation processes (Johannisson, 2003). Yet, in recent decades, an articulation of a greater need for other democratic ideals, such as the promotion of increased participation and greater equality regarding class, race, and gender, has risen in cultural policy (Lund, 2019; Lindström Sol, 2019). Indicators suggest that the principle of artistic freedom/autonomy is increasingly related to the organizational pursuits of equality, diversity, and inclusion in art and cultural organizations. For example, ethical ambiguities regarding artistic freedom and the state of equality have been reported in performing arts (Robinson, 2007). When recruitment announcements (parroting the script's sex and race preferences) are often being perceived as unproblematic through the lens of artistic freedom, they simultaneously engender a negative impact on equality (of cast members in terms of gender, race, and ethnicity) in performing arts (Robinson, 2007). The contradicting notions between ethics of artistic freedom of aesthetic expressions, and the ethics of equality work seem to grow more salient as public-funded cultural organizations are more frequently involved in achieving social objectives of equality than before. A thorough investigation of the equality issues inherent to cultural organizations-where the notion of artistic freedom has been a dominant indicator for ethicality of art and creative work-is timely, relevant, and urgent.

$\overline{1}$ Swedish agency for cultural policy analysis.
Scholars such as Acker (2006) and Ahmed (2007) have explored the emergence and reproduction of inequality categories by pointing out how inequality regimes and dominant values (that sustain existing inequality) may be embedded in commonly practiced organizational processes, norms, and structures. In cultural organizations, much academic inquiry into the issue of autonomy in the arts primarily deals with the art-commerce relation and how artists negotiate and contest market logics (Kleppe, 2018; Røyseng, 2008; Vestheim, 2009). Little attention has been devoted to address the linkage between artistic freedom and the pursuit of diversity and equality, which are both democratic principles yet may collide and contradict each other as states/municipalities/ organizations strive to satisfy multiple democratic goals (Lindström Sol, 2019). Inspired by these notions, for this work, we set out to explore ethical dilemmas between wellintended practices and processes for achieving artistic ethicality and the possible (re)production and perpetuation of inequality regimes (Acker, 2006; Ahmed, 2007). We achieve this aim by taking a close look into the use of the concept of artistic freedom/autonomy and examine how it facilitates or hampers interventions of equality, diversity, and inclusion.

We draw on empirical material from a Swedish publicfunded performing arts body pseudonymized as SNTT. We interrogate the ethicality of practices that are led by the notion of artistic freedom by examining how inequality regimes interlock in normative practices, logics, and rationales in a cultural organization; and how this leads to constructing asymmetrical power relation in a creative artistic process (e.g. Acker, 2006, 2009; Ahmed, 2007). With this aim, we ask the following research questions:

- How do persons in different occupational roles interpret the concepts of artistic freedom, and equality and diversity, in their daily work process?

- How are these interpretive practices related to the power relations in the creative processes?

\section{Ethics, Equality, and the Emergence of Inequality Regimes}

Ethics has become a central focus in organizational studies (e.g. Kornberger \& Brown, 2007; Parker, 2003; Pullen $\&$ Rhodes, 2014). While the discipline of business ethics emphasizes ethics as a means of 'planning, predictability, control and measurement' (see Pullen \& Rhodes, 2015), critical scholars begin to consider ethical matters as an issue for management and organization theory in general (e.g. Pullen \& Rhodes, 2015). They challenge the instrumentalist approach of 'abstract and legalistic schemas [universal ethics] and the emphasis on individualized qualities of behaviour or presentation [virtue ethics]' (Hancock, 2008: p. 1358); and they focus on subjective, 
and intersubjective, expressions of generosity, and how these, in turn, could contribute to a more diverse and inclusive organizational life (Kenny \& Fotaki, 2015; Pullen \& Rhodes, 2014, 2015).

Furthermore, organizational efforts to promote and manage diversity have been subjected to scholarly critique of ethicality (Ahonen \& Tienari, 2015; Zanoni et al., 2010). In work organizations, equality pursuits take various forms, including equality of opportunity, process, and outcome (Greenberg \& Colquitt, 2013). Legislative regulations have been broadly implemented as a frame for equality management strategies at various types of organizations in Europe and the United States (Collins, 2003). Critical Diversity Studies that emerged in the 1990s have since then responded to the ethical issues residing in the pervasive usage of business rationales of equality and diversity pursuits in private and public organizations (Zanoni et al., 2010). Instead of prescribing 'universal laws' of making the best out of 'differences', Critical Diversity Studies investigate ethics issues regarding how difference has been perceived, constructed, and approached within organizations (Muhr, 2008; Tyler, 2018). A large volume of work has been devoted to revealing underlying meaning structures beneath the seemingly empowering approaches of diversity. Scholars within this stream pointed out that the overtly articulated positivity of diversity management may add to reduce awareness of the emergence of inequality regimes such as gender, ethnicity, and socio-economic differences in organizations (Acker, 2006, 2009; Zanoni et al., 2010). For example, scholars have shown how diversity management can be understood as a form of control over 'differences' that contributes to reducing 'others' into categories that support, reinforce or neutralize asymmetrical power relations (e.g. Holck et al., 2016; Romani et al., 2019; Ahonen \& Tienari, 2015). Moreover, the integrative initiatives in diversity interventions are found ethically problematic because they mainly contribute to perpetuating sameness, highlighting the disadvantages of 'others' rather than supporting them (Holck \& Muhr, 2017).

With a different approach, Acker (2006) introduced the concept of 'inequality regimes' in her investigation of organizational practices and processes that result in continuing inequalities in all work organizations. With this concept, Acker (2006) reveals ethical issues pertinent to daily organizational practices by interrogating how inequality indications may interlock into organizations from the material structure to the most common, seemingly neutral organizational practices. According to Acker (2006), inequality regimes are the interlinked practices and processes that foster the systematic disparities between participants in power and control over goals, resources, and outcomes and those who do not enjoy such privileges. The areas that inequality regimes may exert power over are mainly organizing of work, opportunities for promotions, security in employment and benefits, pay and other monetary rewards, respect, and pleasures in work and work relations (Acker, 2006, p. 443).

Furthermore, Acker (2009) points out that in the positions, occupations where women are underrepresented, the concept of inequality regimes more accurately illustrates gender, race, and class barriers that obstruct women's opportunities for advancement at all levels of the organizational hierarchy. For Acker (2006), all types of work organizations may run into risks fostering inequality regimes. The steepness of hierarchies, the degree and pattern of segregation by race and gender, the size of wage differences are all visible indicators of inequality regimes. Yet, while some of the inequality regimes are overt and obvious and are typically suggested by the formal hierarchical material structure of the organization, other aspects of inequality regimes are subtly interlocked in informal interactions and practices (Acker, 2009).

According to Acker (2006), the inequality regimes that are implicit, invisible, and are with fluid and changing bases tend to pose severe ethical issues that may cause perceptions such as unfairness and injustice. Regarding this, Ahmed (2007) further argued that when organizational practices orient around certain marks of privilege (such as whiteness), they become invisible, and the critique of the privilege marks becomes impossible or improper (Ahmed, 2007). Moreover, broadly acknowledged professional rationales function as the mechanism in legitimizing inequalities in subtle ways. Power and class inequalities embedded in hierarchical structures are often legitimized and accepted as normal. Economic and market rationales are also mobilized as the rule of thumb in judging the ethicality although such rationales may contribute to constructing inequalities (Acker, 2006, 2009). The emergence of inequality regimes in an organizational context is often undetectable as it is linked to the common senses in the immediate social, cultural, and political environment, and to the 'normal' practices and procedures that are broadly accepted (Ahmed, 2007). We argue that more attention should be devoted to explore the ethical issues embedded in organizational practices where inequality regimes may emerge in subtle and implicit ways.

\section{Inherent Inequality in Art and Cultural Organizations}

Acker (2006) and other feminist scholars have argued that even organizations that hold explicit egalitarian goals are not exempt from developing inequality regimes over time (Ferree \& Martin, 1995; Scott \& Lane, 2000). This notion further intrigues our inquiry of the ethics of the practices around equality in a cultural organization. In the art and cultural sector, the notion of equality and diversity is paradoxical. On the one hand, diversity is regarded as a vital source of creative inspiration as 'culture is subject to continual reformation 
or it dies; reproduction involves an element of creative practice which involves diversified talents' (Calhoun, 2002, p. 156). On the other hand, the production and consumption of art and culture are inherently unequal (Bourdieu, 1984) in terms of gender, class, and race (Dimaggio \& Useem, 1978).

Some studies from the UK context reported the persistence of social inequalities in the art sector as well as in the creative media industries, showing that female, ethnic minority, and workers with working-class origins have less participation and advancement opportunities (e.g. Gill, 2002; Randle et al., 2007). In performing arts, artists, such as directors, actors, and actresses, often work on temporary employment contracts, and they need to participate in lowwage or unwaged works to increase their visibility in the industry (Miscevic, 2014). This typically enables individuals from middle class with affluent parents to participate in works within the industry but it poses difficulties for those who do not belong to this socio-economical category (Randle et al., 2007). Along with inequality in being granted opportunities in performing arts among women and persons with other ethnic backgrounds, there are also remaining pay gaps by gender and ethnicity in the industry (Eikhof \& Warhurst, 2013; Skillset, 2005). Eikhof and Warhurst (2013) further argued that despite the unequal access to participating in creative work, disadvantage and discrimination in the creative industries are also configured systemically in the model of artistic production.

Moreover, within the creative industries, recruitments are primarily relying on recommendations and social networks. Thus, meritocratic notions of work cannot be fulfilled in the current model of production. As mentioned earlier, the idea of artistic autonomy has been enacted in different types of societal pursuits. For example, Robinson (2007), from a legal perspective, pointed out that the casting process lies at the nexus of two distinctive doctrinal regimes: the rule of protecting artistic freedom and the legislatively regulated employment rules banning hiring decisions based on impermissible factors (e.g. Kimberly, 2004) relating to gender, sex, sexual identity, and expressions. The use of artistic freedom, therefore, creates tension for equality in the context of recruitment and employment concerning discrimination legislation (Chen, 1999; Robinson, 2007: p. 2).

Nonetheless, the use of and the practices connected to the notion of artistic freedom/autonomy have caused ambiguous outcomes that are often connected to the pursuit of the social ideal of equality and diversity. According to cultural policy researcher Johannisson (2003), artistic values have traditionally dominated societal or economic values in Swedish cultural policy, especially on the national level (Kleppe, 2016). From an organizational perspective, professional artists and organizations are the most vocal proponents of the autonomy discourse, often taking the role of free intellectuals opposing the abuse of (political) power (Vestheim,
2009). As a consequence, however, cultural organizations have been found to distinguish between artistic personnel and economic/administrative personnel and where the latter is seen as constituting an ethos threatening the understanding of 'art for arts' sake (Kleppe, 2018; Mangset et al., 2012; Røyseng, 2008).

In Sweden, sociologist Anna Lund $(2013,2019)$ finds that artistic quality and freedom are often used as cultural explanations to why artists would resist gender equality despite being aware of gender disparities in the artistic labour market (Lund, 2019). As a result, although Sweden's cultural norms encourage gender equality, the status quo of male dominance in Swedish theatre is left unchallenged. According to Lund $(2009,2019)$, Swedish cultural policy was exempted from national equality policy with reference to principles of arm's length and artistic freedom. This reveals that the integration of equality perspectives is often seen as threatening artistic quality. Mark (2016) questions this with the argument that unreflective and non-verbalized values are also, besides solidifying the status quo, a threat to quality as making decisions based on democratic values does not govern the artist to make artistic choices but create possibilities to make choices. In cultural organizations where producing arts by following artistic rationales and fulfilling societal democratic ideals assigned by the public are both taken as important missions, the ethicality of work in cultural organizations lies in both the pursuits of social and artistic ideals, competing notions and paradoxes are inevitable. We, therefore, set out to explore the ethical paradoxes in a cultural organization where artistic freedom/autonomy has been a dominant notion and a broadly acknowledged practice in ethical strives.

\section{The Case Study}

The empirical data are generated from a case study of one Swedish public-funded cultural organization SNTT. SNTT has a unique network organization that contains several parts, including one art-producing organization, a nationalwide volunteer association network, and members from the Regional and Municipality Cultural Advisory Board. The organization uses its civic mission, which states 'bringing fine quality performing arts to everyone everywhere in Sweden', as the public manifestation of the equality ambition. In line with the European Union's cultural policies, this civic mission speaks precisely about the organization's dual-directional objectives. While continuously striving for the fine quality of performing arts, after the \#MeToo movement, the organization devotes much effort in establishing and strengthening strategies around equality, diversity, and social inclusion. 


\section{The Empirical Setting and Selection of the Material}

This paper is a part of a 3-year research project financed by the Swedish National Bank's Jubilees Fund. With its focus on equality work and strategies, the research is conducted in a Swedish performing arts company. The first author is the designated researcher for this project who conducted an ethnographic study in the organization in 2018. The apparent advantage of the researcher being an 'insider' of the researched organization is the relatively easy access to interviews and observations (Dwyer \& Buckle, 2009). As an insider researcher, the first author shares the identity, experiential base with the study participants to some extent (Kanuha, 2000; Asselin, 2003). Thus, participants are typically more open with the first author so that the researcher can obtain extensive and in-depth experience-near material, and quickly get familiar with their realities (e.g. Adler \& Adler, 1987; Alvesson, 2003; Aspers, 2009). The unique role as an insider also renders the first author with insights into the organization's approaches to artistic freedom/autonomy.

The second author came into the process while the research was ongoing. With the background in cultural sociology and cultural policy studies, together with the first author, the second author helped to outline a literature background of this paper and actively provided insightful data interpretation together with the first author.

The data collection of the research project concerns the general practices of SNTT's equality work in different domains, such as human resource and administration, artistic production, and volunteer associations. During the two years as an in-house researcher, the first author has interviewed 46 persons, including employees, members of the management group, members of the association organizations, producers, and actors who are permanently employed by SNTT are on temporary project contract terms. She sits in meetings, conferences, and seminars as an observer. There are 65 pages of filed notes being taken during these two years. For this work, we use the first author's field notes for observations regarding the use of the concept of artistic freedom on the organizational level, and we draw on seven interviews of the individuals who are working with artistic processes.

SNTT is located in the southern suburb of Stockholm. The organization consists of major functions such as artistic departments of Theatre, Dance, the Silent Theatre, the Communication and Technique departments, and the support functions such as Administration and Human Resources and IT supports. Like many cultural organizations, the notion of artistic freedom is central. Besides the creative processes, artistic freedom is used in many circumstances such as seminars, educations, and political manifestations related to artistic and cultural work. Sometimes, the term 'artistic freedom' is used interchangeably with the 'freedom of speech' or 'democracy' in the realm of art and culture. For this paper, the material we analyse is selected mainly from the interviews of different actors such as producers, the head of the artistic departments, actors, and the management team members in the professional organization, focussing on different roles in the artistic, creative processes.

Besides the actors, there are three major roles in the artistic, creative processes for performing arts. The head of the artistic departments is responsible for making important decisions on choices of repertoires, selection of dramatists and directors. These major decision-making processes will be followed by establishing a project and the designation of producers in each project group. The producer is the head of the contract, including responsibility for the budget, HR marketing, rehearsal schedule, the touring processes, and other practical matters. The Director appoints actors and scenographers in collaboration with the Artistic Director. Other actors such as technicians and costumers join in the project in a later phase. The administrative functions such as the Human Resource Department are crucial assistance for the artistic process as it bears the administrative responsibilities of advertising, selecting, and recruiting members for the artistic team.

\section{Interviews and Observations}

As mentioned earlier, for this case study, we use both the interview (multiple times) data of seven participants and the field notes of observations for department meetings, organizational conferences, and seminars. Some of the seven (including two producers, three artistic leaders, one actor, and one non-artistic department manager) participants have been interviewed on different occasions. The information of length, occasion, and frequency of the interviews are shown in the table below.

\begin{tabular}{lllll}
\hline $\begin{array}{l}\text { Name } \\
\text { (pseudo- } \\
\text { nym) }\end{array}$ & Position & Gender & $\begin{array}{l}\text { Number } \\
\text { of inter- } \\
\text { views }\end{array}$ & Length of each interview \\
\hline Mary & $\begin{array}{c}\text { Artistic } \\
\text { Direc- } \\
\text { tor }\end{array}$ & Female & 2 & $00: 55: 48 /$ \\
& & & \\
David & $\begin{array}{c}\text { Artistic } \\
\text { Direc- } \\
\text { tor }\end{array}$ & Male & 3 & $00: 43: 36 / 00: 28: 30 / 00: 16: 18$ \\
& $\begin{array}{c}\text { Louise } \\
\text { External } \\
\text { Pro- } \\
\text { ducer }\end{array}$ & Female & $01: 05: 28$ \\
Chris- & $\begin{array}{c}\text { Pro- } \\
\text { dine }\end{array}$ & Female 3 & $01: 25: 52 / 00: 35: 00 / 00: 39: 09$ \\
Angela & Actress & Female 2 & $00: 55: 47$ \\
\hline
\end{tabular}




\begin{tabular}{|c|c|c|c|c|}
\hline $\begin{array}{l}\text { Name } \\
\text { (pseudo- } \\
\text { nym) }\end{array}$ & Position & Gender & $\begin{array}{l}\text { Number } \\
\text { of inter- } \\
\text { views }\end{array}$ & Length of each interview \\
\hline$\overline{\text { James }}$ & $\begin{array}{l}\text { Artistic } \\
\text { Direc- } \\
\text { tor }\end{array}$ & Male & 1 & $01: 22: 52$ \\
\hline Susan & $\begin{array}{l}\text { Com- } \\
\text { muni- } \\
\text { cation } \\
\text { and } \\
\text { Mar- } \\
\text { keting }\end{array}$ & Female & 2 & 00:49:28/ 00:41:06 \\
\hline
\end{tabular}

The interviews all took place when the researcher worked in the same office building as all participants. Each interview lasted around $60 \mathrm{~min}$. The first author informed the participant about the research and the use of the data. The semi-structured interview guidelines are customized for different roles each person occupies in the artistic process. The typical questions being put forward are including: 'what is your interpretation of artistic freedom'; 'do you practice such freedom/autonomy in work processes?'; 'why? And why not?' Furthermore, the semi-interview structure leaves open space for participants to illustrate events that are related to the notion of artistic freedom and are crucial for their personal experience of (in)equality. An intriguing observation during the research is that while the discussion about the linkage between artistic freedom/autonomy and equality goes deeper, the participants often began to reflect upon the notion differently. For example, one theatre actress responded to the first author that before the interview, she followed the industry's unspoken rules and took for granted that the artistic freedom exclusively belonged to the directors who occupied the informal top-position in production processes.

The individual participants for the chosen interviews worked on different artistic projects. The interview occasions were not intentionally planned, but upon the convenience of the participants as some of them are often occupied while working with an ongoing production project. The recruitment for the next participants often follows a snowball principle. The first author's position as the in-house researcher has benefited the participant recruitment process, too, due to familiarity between the researcher and participants in daily encounters at one workplace.

Moreover, in the interviews, the first author used the term 'artistic freedom' more frequently as this is the term that addresses the personal experience of free expressions of art. The term artistic autonomy has also been used when the discussion is more focussed on the policy-making dimensions and philosophical reflections of art. The first author focussed on understanding firstly, how each individual interprets the meaning of artistic freedom; secondly, how they relate the concept to their role in the creative process; and thirdly, how they, when describing their practices in the creative process, identify their role and acknowledge the decision-making power. Moreover, the interviews are held in Swedish. The transcriptions of the interviews are in Swedish, too. For this work, parts of the interview materials are translated into English by the authors.

\section{Interpretation and Analysis}

We use interpretive phenomenology as the methodological touchstone for this work aiming to investigate what made invisible, habitual, and familiar about the world that is 'around' (Ahmed, 2007: p. 151; Aspers, 2009), and through that inquiry, spotlight why that which is invisible may also be improper. We take the role of language as a vehicle for actors expressing their understanding and interpretation of the situation; it is an intermediate means for the researcher to understand the realities of others (Schütz, 1964), that is, the 'first-order construct'. The analysis of this study has been undertaken into two interrelated steps (e.g. Aspers, 2009). Firstly, we made a close reading of the transcribed material, focussing on understanding interpretations of artistic freedom and diversity. The next step was to enact the theoretical frame to interpret the first-order construct, with which we revealed the underlying meanings by presenting the secondorder construct (Schütz, 1964; Aspers, 2009).

The interpretive framework is mainly inspired by Acker's (2006) notions of inequality regimes. Thus, we focus on examining how inequality regimes emerge from mundane practices and processes, relationships, and power (both visible and invisible) structures. In addition, Ahmed (2007) grants a phenomenological perspective on the shape of that which is made invisible in institutional spaces. With this, we can understand why certain bodies cannot be recruited without being 'out of place' (Ahmed, 2007, p. 159) such as a tool for the institutions' strive for inclusiveness; and why certain (white) bodies can be recruited as a 'pure' choice of artistic freedom, as free from other considerations than aesthetic quality. Furthermore, to understand the meaning making of artistic freedom and autonomy in the material, we pay attention to elements such as how certain privileges become invisible to those who inhabit it (c.f. Ahmed, 2007).

As inequality regimes are highly fluid and changing (Acker, 2006), some of the disparities between individuals in power and those who are not are overtly being demonstrated in work relations, whereas others are not always evident. In an artistic, creative process, there is often a lack of formal hierarchical decision-making structures. The formations of asymmetrical decision-making structures are associated with practices and interpretations developed in specific cultural or organizational contexts (Acker, 2006). Thus, we try to capture the formations of inequality regimes by analysing both 
the organizational context and individuals' use of artistic freedom in that context.

\section{Results}

\section{Artistic Freedom as a Manifestation of the Ethical Commitment to Aesthetic Expressions}

We find that the use of 'artistic freedom' is ubiquitous in artistic, creative processes, and formal and informal daily conversations in SNTT (c.f. Johannisson, 2003). Despite vaguely defined, the notion of artistic freedom is taken as both the ultimate objective and the driving force in organizational processes by individuals in different roles. Respondents are unanimous about the status of the mission in terms of sustaining absolute artistic freedom/autonomy and intend to incorporate this notion in all working processes.

On an organizational level, we find that SNTT establishes its public communication strategies by strictly conforming to the major principles outlined by the European Union and the Swedish national cultural policy to render equal opportunities for people to participate in artistic, creative work regardless of their background or income. In internal seminars, conferences, or meetings, the first author has observed that the notion of artistic freedom/autonomy is often brought up as an expression of organizational commitment. For example, the phrase is embedded in a speech typically expressing: 'we will work to maintain the utmost level of artistic freedom...by upholding artistic freedom, we will provide performing arts with fine quality to people'. Statements as such are often used without a specific explanation. Yet, this seemingly rational statement contains contradicting implications.

First, we find that the use of the notion of artistic freedom/autonomy in SNTT is heavily influenced by the Kantian concept of 'art for the sake of art' (Belfiore \& Bennett, 2007). While this statement emphasizes freedom from political and market pressures, it also claims the authority of the judgement of 'fine quality' of performing arts. Thus, this approach implies that all external factors (concerning the intrinsic, cognitive process of artistic creation), such as political influence, market pressure, and social ideals such as equality work, are possible threats to the ethics of artistic freedom/autonomy. As a consequence, the ambiguous use of artistic freedom/autonomy results in difficulties in collaborative works. Individuals involving in different organizational tasks struggle to define the priorities and focuses as multidirectional objectives, such as producing quality performing arts, fulfilling market demands, and achieving the social ideal of equality. As such, Susan, from the Communication and Marketing Department expressed her struggles attempting to find a focus and direction in her work:
It has been difficult for me to find an integrated focus in my work as everyone tends to pull from different directions. Of course, there is an obvious high status and priorities for artistic work. But then when we try to 'bring fine quality art to everyone everywhere', we wonder who decides what people would like to have?

Second, we find that little emphasis and explanation have been designated to unpacking the subject of artistic freedom/autonomy in a production process. As performing arts productions are processes of close collaborations of a group of individuals (artists), it is important to understand whose freedom is privileged in an artistic process and whether others' artistic freedom may be compromised. Yet, differing from formal power relations that are indicated by the hierarchical structures, the authority in an artistic, creative process is covert and often taken as a 'common-sense' practice. This leads to the invisibility of inequality. The privilege of decision making that spills over the artistic domain is also legitimized (e.g. Acker, 2006; Ahmed, 2007). We detect a tendency that the ambiguous use of artistic freedom legitimizes and perpetuates differentiated status between artistic and administrative workers (Ahmed, 2007). Moreover, it results in forming unspoken rules of practice and informal power relations in work processes, which, in turn, enforces centralized authority and decision making and maintains inequalities within the organization (e.g. Acker, 2006). For example, according to both internal and external producers, people tend to refer to the authority of art and aesthetics not only for artistic guidance but also for recruitment of cast members and decisions of wage and salaries of the casting members.

Furthermore, as Acker (2006) indicated, inequality regimes are changing and are often linked to inequality in the surrounding society, politics, history, and culture, following the development of particular practices and interpretations in the organization and its subunits. Today, public-funded art and cultural organizations are more closely associated with societal responsibilities while facing increasing market pressures like organizations in the private sector. This requires organizations to adjust their strategies and practices to fulfil multiple objectives. We find intriguing in the case of SNTT that the taken-for-granted notion of 'art for the sake of art' has been broadly used in most events in the organization as a non-problematic ethical manifestation. Although being well intended for emphasizing the importance of artistic freedom, practices as such implicitly and subtly sustain the general belief of artistic aesthetic authority in the wider society (e.g. Mark, 2016). Yet, this approach obscures the organization's focus on developing holistic strategies and fulfilling other societal demands. More importantly, it facilitates the formation of an unspoken ethical hierarchy, which implies artistic work is generally ethically superior to other types of tasks 
in the organization. This, in turn, may result in systematic disparities in terms of the control of goal, resource, outcome, and distribution of benefit and wages, which are indicators of the inequality regimes linked with participants' decisionmaking power in an artistic process (Acker, 2006).

\section{Artistic Freedom as Camouflage for Centralized Aesthetic Authority in Creative Processes}

On an interpersonal level, we find that the meaning making of artistic freedom often relates to articulations of freedom of speech and expression. This democratic value encompasses all who are inclined to express themselves artistically in some way or another. This use of 'artistic freedom' corresponds to what we label as expressionist justice, emphasizing the right for all with the inclination to be creative and have something to express, to have the right to pursue life and identity as an artist, to identify as an artist and to play a role in society as an artist. As this notion is closer to the national cultural goals of 'culture for all' (Prop, 2009:10), consequently, impeding this right is an injustice, such as preserving the right to be an artist to a certain segment of the population or a person in a certain position in a hierarchy. For example, Mary, one of the Artistic Directors, opened her conversation with the researcher by elaborating how she understands the notion of artistic freedom.

I think artistic freedom ... to some extent is related to freedom of expression for my part and the free world. If I think that I am an artist and I make a performance or an object and claim that it is art, then I think it is art. It is not always certain that there is some institution or art hall that wants to show it, but at least I got to express myself artistically. I think we are all entitled to that.

Leading an artistic process is, however, different. I am the decision maker here. You see, I just cannot let all types of bodies to be on the stage to present all types of dance genres, you know what I mean. For some traditional western dance, only some bodies would be suitable. So, I have to make the decision on that choice.

Mary is not alone in terms of setting legitimate ground by enacting the democratic values of the concept of artistic freedom. Many other correspondents use the term in similar ways to emphasize their focus on the democratic ideals in art and cultural work. However, as Mary pointed out, in actual practices in the creative processes taking place at SNTT, the understanding of artistic freedom gains a different meaning. A respect for hierarchies of power often overshadows the notion of expressionist justice. In this case, Mary executes the artistic decision-making power by allocating different bodies for different dance genres based on her understanding of the tradition of the art (Ahmed, 2007).

Consequently, people with other bodies, colours, and races conform and accept 'inequalities' that are enforced upon them in the name of artistic freedom. For example, Angela, a theatre actress of a Latin-American origin, feels she is largely dependent upon the recommendation and inclusion of the theatre Directors. She admits that she has rarely reflected upon her artistic freedom but trusts that it is the decision of the Directors to place her in the 'right' places and scripts.

I am grateful that I get jobs. You know, as a LatinAmerican, with my hair and look, I don't easily get to be included in every play. There has to be the scripts that suit me. I am grateful that some directors see my quality over my ethnicity and appearance.

The process of an artistic event, such as a theatre performance, is perceived as the summary of a series of aesthetic choices. Aesthetic authority is our articulation of the expressed necessity of decision power over aesthetic choices to certain people in the organization, to the extent where abuses of this position of power seem impossible to protest or oppose. Although there is no formal hierarchical structure in artistic processes at SNTT, and the right of artistic freedom is alleged to apply to all members of the team, we find that the cast members (including actors, producers, costume and scenographers) unanimously hold the view that the Director of a theatre play holds the privilege of artistic freedom in a hierarchy of relations (Bourdieu, 1996; Mangset et al., 2012).

Artistic freedom is then an exclusive authority or privilege of the Director who 'decides on' things (Bourdieu, 1996). Looking at how artistic freedom is articulated in relation to everyday work in the cultural organization, we detect a different interpretation that emphasizes the importance of decision power over aesthetic choices to certain people. Although there is no formal structure of power in the organization regarding power over aesthetic influences, the aesthetic choices are ultimately taken by a person in charge, normally the Director. In falling order, others have the right to influence artistic choices if they have a role in producing artistic content. Thus, despite the existence of the expressionist justice articulation, the organization employs an unofficial division of labour where artistic choices are the privilege of one person who is placed on the top of an outspoken hierarchy of influence over artistic processes. This position of power in decision-making offers the ability to ignore aspects of inequality regimes, such as fairness in recruitment processes. Louise, an external producer who has worked on several projects at SNTT, confirms our observation in her statement: 
You won't get any formal document indicating 'who is the boss,' but I think the formal power lies in the hands of the Directors. They are the real project leaders who have the trust of the cultural organization, which are assigned with both the responsibilities and power by the art producing organization or by specific, influential persons in that organization. Yes, they are the real 'bosses' in the artistic project.

This quote confirms that it is the 'decision maker', the Director, who exclusively enjoys the artistic freedom and embodies hierarchy structures in the seemingly meritocratic context. It is a position informed by the classic notion of genius in the autonomous tradition, a role historically almost exclusively reserved for white men (Belfiore \& Bennett, 2007; Flisbäck, 2013; Myndigheten för kulturanalys, 2015). This informal decision-making structure, and thus this articulation of artistic freedom, is legitimized based on the understanding that it safeguards artistic quality, which is another important part of the Swedish national cultural goals (Prop. 2009/10:3). However, the structure creates an inequality regime with aspects such as patterns of segregation and power differences where some have restricted opportunities for influence. Although some respondents acknowledge these issues, the hegemonic position of artistic freedom as aesthetic authority offers little opportunity for resistance. Instead, they need to be 'players of the game'. Thus, we find that artistic freedom is interpreted as and used to designate aesthetic authority.

Based on the principle of artistic freedom, depending on people's position in the organization, they can voice concern over what works and not regarding scenes and dialogue and influence, especially when they express worries for the quality of the finished project. However, ironically, cast members, while referring to 'artistic freedom', tend to give up their influential voices in the creative process voluntarily. Christine is an experienced producer who has worked in the organization for over ten years. Her responsibility is to take care of all practical matters in a producing process, including coordinating collaboration between different theatrical departments. Although knowing the repertoire from front to back is a premise for her work, she does not see herself as part of the creative, core members:

Oh, I thought artistic freedom is not relevant to my work; this is the matter for Directors. It depends on what relationship you have to the Director and how much you can talk, but there may be some things (...) "oh, why did you remove that scene, it was so damn good. It was so nice," or something like that (...) But ... the Director has to decide for himself whether to change it or not.

I take care of things, but I do not create artwork. It is the Director who creates. But I always read the manuscript, of course. I need to know what kind of work each department should deliver according to the manuscript. Sometimes when I am familiar with the Director, I might tell my opinions about, for instance, the costume or even scenography.

As a producer working with the most practical duties in a production process, Christine is well aware of the underlying power distribution in a production team.

There are no formal rules or an organizational chart in a production process, but everyone understands how to play the game. I am not one of the 'artistic members,' so I just do my duties and responsibilities. But of course, there is an unspoken power structure, and the Director sits on the top of it.

Similar to Christine, Angela, responded to me with a very modest attitude regarding her interpretations of 'artistic freedom':

I actually do not think about it very often. It is up to the Director to make decisions on different roles. I am simply happy to be included in production. I often try to deliver what the director crafts. I guess it depends on whom you work with. I might be able to make some influence when I know the Director is fine with it. I did make them change the costume for my role once. And in my most recent performance, the Director made some changes to my script so that it suits my personality better.

The quote of Angela simultaneously reflects a sense of insecurity as a professional actor. The recognition and opportunities of work in performing arts are reliant mainly on network relations (e.g. Thanki \& Jefferys, 2006-07; Miscevic, 2014). The core members of the casting team are often handpicked by the Director. It is, therefore, understandable that Angela feels 'grateful' to be part of the cast and avoid questioning the aesthetic authorities. Such concerns may be hidden underneath her 'voluntarily' designating the right of artistic freedom to the Director, who represents the ultimate aesthetic authority.

Moreover, we detect that the formal administrative authority voices the support of the power of aesthetic authorities by using 'artistic autonomy', which strengthens the trend of centralization of aesthetic authorities. For example, typically, as the decision maker of choices of Directors for an upcoming performing art project, one Artistic Director from SNTT expressed his full trust in both the artistic qualities and the integrity of the persons(Directors) of choices:

They have my full trust and support. They are prominent and competent artists. They have full freedom in the creation process. I hope they can consider equality, 
diversity and inclusion in their artistic creation, but it is within their authority to execute the artistic freedom so I should not interfere. If one production lacks the equality scale, I will try to make sure other productions can show a better result. I might give a very mild reminder. But then I will leave them alone.

Nonetheless, whereas people seemed to be unanimous about the possession of artistic freedom and recognized the power of the 'person in charge', they occasionally voice dissatisfaction and challenge the central aesthetic authority. When other members than the artistic authorities make an aesthetic judgement, their power to influence artistic processes and decisions is later limited. Some witnesses having agreed-upon choices made in the dialogue are later revoked without explanation. Louise, the external producer, gave an example of situations of injustice:

In the project where I got the most attention, I believe it was all because of another colleague who was unfortunately not being fairly treated. He gave all the creative ideas but not a proper background. We had difficulty providing him employment in the project mean, they worked out a form of employment for him, eventually, but it took a long time, and the solution could not justify his contribution to this project.

This encounter results from interpreting someone's artistic freedom claiming the sole power to the 'aesthetic authorities' who primarily extinguish themselves through specific educational merits (having the right educational merits from the right school). At best, this serves a legitimate division of labour where the chain of decision power serves quality in aesthetic processes (Acker, 2009). The interpretation of artistic freedom as the aesthetic authority is seldom questioned, evident in the way, many respondents express surprise regarding questions about artistic freedom and how they seem to have seldom reflected upon this notion. At worst, aesthetic influence from people without the formal merits to occupy the role of aesthetic authority is made invisible, and their contribution to the artistic process is downplayed and attributed to the person on top of the hierarchy. Hence, the meaning making of 'artistic autonomy' as aesthetic authority strengthens a centralized decision power in artistic, creative processes in a chain of power that impedes efforts to compensate those exposed to injustices regarding aesthetic influence and work.

\section{Artistic Freedom and the Formation of Inequality Regimes that Hamper Differences}

We detect a set of dichotomies constructed in the discursive formulations of artistic freedom when the term is related to the topic of equality, diversity, and inclusion. Diversity is either constructed as 1. For art (and thereby compatible with expressionist justice), or 2. Against art (incompatible with aesthetic authority). In other words, issues of diversity, equality, and inclusion were mostly articulated as opposed to artistic quality, and therefore, incompatible with the hegemonic position of aesthetic authority. This set of dichotomies illustrate matters around equality, diversity, and inclusion as opposed to artistic quality. This, in turn, gives legitimacy to injustice and unfairness in the artistic, creative process, and other processes that are closely associated with it, such as the selection of cast members, decisions around salary and wages, and other practical and aesthetic choices.

We find that persons who occupy the manager position take on the role of the 'balancer' in making decisions regarding the two seemingly opposing notions between art and equality. David, an Artistic Director at SNTT, expressed his dilemma in weighing the two 'equally important' matters:

In this position, I am responsible for taking care of several important aspects at the same time. While considering the importance of issues around equality and diversity, I need to respect artistic freedom, too. So, if I see a casting team which does not contain diverse members, I do not want to pressure the Director but hope we can do better in the next project.

Similar to David's other quote, this one shows his trust and respect for the ultimate aesthetic authority, the Director. He justifies the possible inequality in the recruiting process by claiming to protect the democratic ideal of artistic freedom. Thus, as the 'balancer', David incorporates and harmonizes the different democratic ideals of artistic freedom. This results in that the hegemonic position of aesthetic authority is carefully preserved, even in recruitment situations that go against official guidelines since recruitment via networks is known to perpetuate inequalities (Acker, 2009; Myndigheten för kulturanalys, 2015). Being an artistic leader, David's attempt to balancing the interpreted dichotomy between art and equality defines the meaning of artistic freedom. However, the centralized authority for interpretations of artistic freedom hampers possible concerns over inequalities in artistic projects, such as control over resources, the organization of work, opportunities and benefits, pay and other monetary compensations etc. (e.g. Acker, 2006; Ahmed, 2007).

Nonetheless, the dichotomized notions of 'art' and 'equality' cause various confusions in daily work practices. Christine, the internal producer in SNTT, expressed her struggles when she attempted to incorporate the ideal of equality with the concept of artistic freedom in the following way:

Many artists come with baggage and some experience from other institutions, and sometimes they believe things ought to be done in a certain way. And then I stand there a bit like a goalkeeper, or an ambassador and say "no, but we are open to equality and we are different from the rest". And then as soon as you 
start scratching a bit on the surface you will notice that there are still older structures, then you also have to be able to defend it in a good way.

Furthermore, David expressed dilemma regarding the diversity of audiences and the quality of 'true art':

We need the repertoires that address equality and diverse audiences. This is the only way for us to meet the audience. So, we, as an institution must be relevant to the audience whom we want to reach. If we are to be relevant, and it is both an artistic and democratic mission. And here you cannot distinguish between them. So, there is a debate on whether the artwork should be just artistic. But it is the tax money we get, we have to produce for everyone everywhere, and we also have to reflect the reality of society, with all its complexities. One producer simply cannot fulfil all missions just within one year, reflecting the entire complexity of the society.

The above quote expresses how the value of art is not only exclusively determined by the art world but also gains importance from its audiences. This, in turn, relates to the interpretation of the concept of art and who art is for. SNTT is a public-funded organization, and it needs to orient itself in relation to legislation and government cultural policy goals, formulating the understanding of culture as an expressionist justice; everyone should be able to enjoy, create, and experience art (Prop. 2009, p.10). The general notion of art and work of art, however, entail 'art for the sake of art' tradition with no other embedding purposes than itself (Belfiore $\&$ Bennett, 2007). This, too, becomes a set of dichotomies where interpretations of equal access to art and artistic freedom are constructed to contradict each other.

This leads to a persistent tension between artistic freedom and considerations of equality, diversity, and inclusion. James, another Artistic Director at SNTT, talked about one audition they did outside Sweden. In this excerpt, both interpretations of equality for art and equality against art are used.

You see, we would like to include all kinds of bodies on the stage. This is both important for dance and also for equality matters. Although we assure everyone that they are here with us because of their dance technique, not the tokenism of a type of body, we also realize that we do include them for a reason. For example, when one of our black dancers chose to leave one production, my colleague said to me "now we have to look for a black dancer'. So you see, we try to achieve equality, diversity and inclusion without the expense of quality in art, but it is both difficult and complicated.
The quote shows an example of which equality, diversity, and inclusion are not compromised for the insistence of artistic freedom; rather, it is viewed as a supplement to the quality of the art. Aiming to attract people from diverse backgrounds, James sought the opinion of the organization's strategist of equality matters. However, James, who identifies himself as both the administrator and an artist, struggles to articulate a mutual existence of the political ideal and goodness of art as if it violates the true meaning of 'art for the sake of art' (Belfiore \& Bennett, 2007):

We asked for suggestions for formulating an advertising text for an audition. The intention is to attract people with different types of dance training, body shapes, forms, colors. This is both for consideration of artistic quality and for equality. However, when my dancers' ask me whether they are picked for their skin colour or dance technique, I always ensure them that it is their dance skill that caught my attention. You see, the equality part can be sensitive. I don't want people to feel they are representations.

Obviously, in performing arts, inequality regimes do not only emerge from formal structures and processes, but are also implicitly embedded in mundane decision-making processes in auditions and selections in daily routines that are often oriented around 'whiteness' (Ahmed, 2007). In James' and David's dilemma, we read out that artistic quality is viewed as a factor bringing legitimacy to a cultural organization, more so than diversity, which explains the reason why it is seen as of higher value. The dancers acknowledge this hierarchy of value and oppose the idea that the presence of their bodies is but a signal of organizational commitment to equality and diversity (Ahmed, 2007). Furthermore, the concerns often are related to the notion of representation. Respondents generally react negatively to the concept of representation, as it is related to values outside the artistic process, which is hegemonically constructed as belonging to specific individuals who are predominantly white men (Myndigheten för kulturanalys, 2015; Robinson, 2007). We find that the producers usually accept the interpretation of artistic freedom as aesthetic authority to the extent that they find it a bit difficult to put into words. Their expressions of experiences confirm our concerns. As Louise, the external producer stated:

On the stage or in what we present, you can see quite good presentations of 'equality, diversity and inclusion'. However, during the working processes, the artistic creation processes, I have experienced many unequal and unfair incidences behind the stage.

This above quote validates concerns of possible inequality regimes hidden beneath a well-presented image of diversity (Ahmed, 2007). It also further reveals the complexity and 
ambiguity in SNTT's attempts to achieve social and artistic democratic goals.

Our finding indicates that art and diversity are interpreted more as opposite notions than mutually benefiting each other in the creative processes. The pursuit of equality and diversity is constructed as a social objective subordinate to the 'cognitively' intrinsic artistic arrangement of art. This explains why they may 'collide' (Lindström Sol, 2019), and at times the former may be eliminated as the expense of preserving the latter, the more superior artistic objective. The Swedish cultural policy has a history of equating art with qualitative art (Johannisson, 2003). This macro-level elusive concept of quality may, to some extent, contribute to the construction of artistic autonomy in opposition to the democratic value of diversity on and behind the stage. However, we concern that individuals in artistic processes sustain and strengthen the separation between the ethics of artistic freedom (which is seen as the equivalence of the premises of qualitative art) and the ethics in the work of equality, diversity, and inclusion.

\section{Discussion}

The implicit, invisible inequality regimes with changing bases are seen as the source of severe ethical issues linked with unfairness and injustice (Acker, 2006). In this article, we explored ethical issues residing in the taken-for-granted assumptions of the notion of artistic freedom by unravelling the subtle, invisible forms of inequality regimes (c.f. Ahmed, 2007). Our case study shows that there is an imbalance between the organizational pursuit of ethics of artistic freedom and that of equality and diversity work. Artistic freedom has been constructed to give the right and authority to some individuals to make aesthetic and artistic choices. This is considered legitimate as it functions as an ethical safeguard for producing artistic quality; however, it simultaneously hampers awareness of inequality and any initiatives of change to the system (Lund, 2019; Robinson, 2007). Thus, in this case, inequality regimes emerge not from the disparities embedded in the visible and material power structures but from the broad and ambiguous uses of the concept of artistic freedom. These regimes are subtly interlocked in a system where people believe that they preserve the ethics of artistic quality by defending a valued democratic ideal.

Relating to the notion of inequality regimes, we find that firstly, the hegemonic interpretation of artistic freedom lays an authoritarian base for the emergence of inequality regimes. Although participants' articulations of artistic freedom mainly related to the democratic ideal of freedom of speech and the right for everyone to express themselves artistically, we find such expressions are subordinate to an understanding of centralized aesthetic authority. Individuals occupying different artistic roles in art and creative process unanimously give the artistic decision-making power to the informal leadership structure, which is mainly constituted by the producer (financer of the art project) and the Director. This concentrated power structure is, in turn, being perpetuated by continued use of the vaguely defined concept of 'artistic freedom', which is loosely and exclusively connected to the Kantian idea of 'art for the sake of art'. Here, the paradox of the pursuit of the freedom of articulating artistic opinion and the centralized aesthetic authority facilitates the emergence of disparities in creative working processes, which are often covert, invisible, and constantly legitimized.

Furthermore, our findings show emerging bases for inequality regimes in terms of 'class' (e.g. Acker, 2009). The directors of performing arts projects are given not only the aesthetic authority but are in control of the resources such as the decision-making power in the recruitment of cast members, the distribution of casting roles, and in some cases the influencing power of salaries and wages for cast members. Resources may be unequally distributed through crucial processes such as selecting the cast, wages, salaries, and other forms of transfer; thus, class differences are produced as these essential processes take place (c.f. Ahmed, 2007). Thus, we see this contribute to the ethical issue of 'class' when enduring and systematic differences in access to and control overproduction of goods and services are taking shape (e.g. Acker, 2009, p. 202). While the production of class is intrinsic to employment and to most organizations following a formal hierarchical structure (e.g. Acker, 2009), our work suggests that, in art and creative process, the production of class divisions is not congruent with a formal administrative power structure but is achieved through both individuals' voluntary designation of the decision power to a few persons, and these few persons' repeated execution of the designated 'artistic authority'. In this process, the use of artistic freedom is an essential legitimator, which eventually contributes to the construction of an informal power structure with a few individuals (often white males and females) on the top (e.g. Acker, 2009). This informal structure may effectively silence the voices of resistance or different artistic opinions and reproduces class, gender, and ethnic bases for the inequality regimes.

Second, our findings suggest that using the concept of artistic freedom without specific definitions creates contradicting interpretations between artistic freedom and the pursuit of equality, diversity, and inclusion (e.g. Acker, 2009). This poses a delusive ethical dilemma that artistic freedom and equality pursuits are exclusive choices to one another, and the ethicality and quality of the artwork will only be preserved at the expense of dismissing efforts for equality. The ethical dilemma as such sustains the status quo of systemic inequality in the organization. We see this as a risk 
that potentially contributes to perpetuating the severity of power differences, restricting opportunities for some people, engendering stereotyped expectations for behaviour, and inducing exclusion tendencies (e.g. Acker, 2009).

Finally, we argue that the application of the loosely defined notion of artistic 'freedom' (by a few persons) may contribute to the status quo of unequal conditions within the cultural sector in terms of gender, race, and class. It generates exclusiveness, the authority of the artistic work, and the fear of the outsiders for making any critique towards creative works. We also call for scholarly attention to the formation of the type of hegemony in art and cultural organizations that rules not only aesthetic decisions but also other organizational processes such as selection, incentives, and work opportunities. This hegemony may hamper the fulfilment of both ethics of free expressions of artistic opinion and organizations' pursuits in equality, diversity, and inclusion.

\section{Conclusions}

To conclude, although artistic freedom is a vital aspect of a democratic society, when it is interpreted and used in certain ways, it may nurture systematic (re)producing and perpetuation of the informal asymmetrical power relations in artistic, creative processes. Consequently, the ethics of artistic freedom become obscured (as a privilege for only a few members in the artistic process) and the ethicality of equality, diversity, and inclusion will also be jeopardized.

However, the purpose of this paper is not to question or subvert the democratic importance of artistic freedom. We are fully aware that the issue of undue political interference in artistic decision making and content is currently actualized in different states in Europe and remains a serious concern. Instead, we question the taken-for-granted ethical assumptions embedded in the artistic work-which is solely built upon Kantian notions of the aesthetic quality of the production or exhibition and is presented in the form of free expressions of an intrinsic cognitive experience. In the increasingly globalized society, this narrowly defined concept of artistic freedom is found colliding with the social ideal of equality, diversity, and inclusion. The \#MeToo movement has prompted important questions in this respect, too. Ethical issues within the art and cultural organizations are not merely isolated incidences that are related to the single aspect of individual morality. As we argue in this work, well-intended democratic ideals of artistic autonomy can be mobilized in interpretative practices to defend the status quo and curb measures directed at equalizing decision power in the organization regarding structures of race, class, and gender-i.e. un-democratic and unequal goals. With this critique, and the scrutiny of centralized power in artistic, creative processes, we call for more research to explore the formation of invisible inequality regimes that are subtly interweaved in the alleged ethical arrangements and the impact of such regimes on a broader scale.

Acknowledgement This study is funded by the Flexit Project of the Swedish Riksbankens Jubileumsfond: RMP18-1034:1.

Funding Open access funding provided by Linköping University.

Open Access This article is licensed under a Creative Commons Attribution 4.0 International License, which permits use, sharing, adaptation, distribution and reproduction in any medium or format, as long as you give appropriate credit to the original author(s) and the source, provide a link to the Creative Commons licence, and indicate if changes were made. The images or other third party material in this article are included in the article's Creative Commons licence, unless indicated otherwise in a credit line to the material. If material is not included in the article's Creative Commons licence and your intended use is not permitted by statutory regulation or exceeds the permitted use, you will need to obtain permission directly from the copyright holder. To view a copy of this licence, visit http://creativecommons.org/licenses/by/4.0/.

\section{References}

Acker, J. (2006). Inequality regimes gender, class, and race in organizations. Gender and Society, 20(4), 441-464

Acker, J. (2009). From glass ceiling to inequality regimes. Sociologie du travail, 51(2), 199-217

Adler, P., \& Adler, P. (1987). Membership roles in field research. Sage. Ahmed, S. (2007). A phenomenology of whiteness. Feminist Theory, 8(2), 149-168. https://doi.org/10.1177/1464700107078139

Ahonen, P., \& Tienari, J. (2015). Ethico-politics of diversity and its production. In A. Pullen \& C. Rhodes (Eds.), The Routledge Companion To Ethics, Politics And Organizations. (pp. 271-287). Routledge.

Alvesson, M. (2003). Methodology for close up studies-Struggling with closeness and closure. Higher Education, 46, 167-193

Aspers, P. (2009). Empirical phenomenology: A qualitative research approach. The Indo-Pacific Journal of Phenomenology, 9(2), 1-12

Asselin, M. E. (2003). Insider research: Issues to consider when doing qualitative research in your own setting. Journal for Nurses in Staff Development, 19(2), 99-103

Belfiore, E., \& Bennett, O. (2007). Rethinking the social impacts of the arts. International Journal of Cultural Policy, 13(2), 135-151. https://doi.org/10.1080/10286630701342741

Bourdieu, P. (1984). Distinction: A social critique of the judgement of taste. (R. Nice, Trans.) Cambridge, Massachusetts.

Bourdieu, P. (1996). The rules of art: Genesis and structure of the literary field. Polity Press.

Calhoun, C. J. (2002). Imagining solidarity: Cosmopolitanism, constitutional patriotism, and the public sphere. Public Culture, 14(1), 147-171

Chen, B. (1999). Mixing law and art: the role of antidiscrimination law and color-blind casting in broadway theatre, 16 HOFSTRA LAB. \& EMP.L.J. 515. Note (discriminatory practices in theatre)

Collins, H. (2003). Discrimination, equality and social inclusion. The Modern Law Review, 66(1), 16-43

Dimaggio, P., \& Useem, M. (1978). Social class and arts consumption. Theory and Society, 5, 141-161. https://doi.org/10.1007/BF017 02159 
Dwyer, S. C., \& Buckle, J. L. (2009). The Space between: On being an insider-outsider in qualitative research. International Journal of Qualitative Methods, 8(1), 54-63

Eikhof, D., \& Warhurst, C. (2013). The Promised Land? Why social inequalities are systemic in the creative industries. Employee Relations, 35(4), 495-508

Ferree, M. M., \& Martin, P. Y. (Eds.). (1995). Feminist organizations. Temple University Press.

Flisbäck, M. (2013). Creating a life: The role of symbolic and economic structures in the gender dynamics of Swedish artists. International Journal of Cultural Policy, 19(4), 462-480. https://doi. org/10.1080/10286632.2012.658046

Gill, R. (2002). Cool, creative and egalitarian? Exploring gender in project-based new media work in Europe. Information, Сотmunication and Society, 5(1), 70-89

Greenberg, J., \& Colquitt, J. A. (2013). The handbook of organizational justice. Erlbaum.

Government proposition 2009/10:3, Tid för kultur [Time for culture]. The Swedish Riksdag

Hancock, P. (2008). Embodied generosity and an ethics of organization. Organization Studies, 29(10), 1357-1373

Haskins, C. (1989). Kant and the autonomy of art. The Journal of Aesthetics and Art Criticism, 47(1), 43-54

Holck, L., \& Muhr, S. (2017). Unequal solidarity? Towards a normcritical approach to welfare logics. Scandinavian Journal of Management, 33(1), 1-11

Holck, L., Muhr, S., \& Villesèche, F. (2016). Identity, diversity and diversity management: On theoretical connections, assumptions and implications for practice. Equality, Diversity and Inclusion: An International Journal, 35(1), 48-64

Johannisson, J. (2003). Lokal kulturpolitik-ett senmodernt identitetsprojekt. In S. Sörlin (Ed.), Kulturen i kunskapssamhället Om kultursektorns tillväxt och kulturpolitikens utmaningar. (pp. 139-160). Nya Doxa

Kanuha, V. K. (2000). "Being" native versus "going native": Conducting social work research as an insider. Social Work, 45(5), 439-447.

Kenny, K., \& Fotaki, M. (2015). From gendered organizations to compassionate borderspaces: Reading corporeal ethics with Bracha Ettinger. Organization, 22(2), 183-199

Kimberly, A. Y. (2004). Private nurses and playboy bunnies: Explaining permissible sex discrimination. California Law Review, 147, $149-154$

Kleppe, B. (2016). The autonomous world reversed: Comparing liberal policy and autonomy in the performing arts. International Journal of Cultural Policy. https://doi.org/10.1080/10286632. 2016.1184659

Kleppe, B. (2018). Managing autonomy: Analyzing arts management and artistic autonomy through the theory of justification. The Journal of Arts Management, Law, and Society, 48(3), 191-205. https://doi.org/10.1080/10632921.2017.1377661

Konstnärsnämnden (2016). Konstnärernas demografi, inkomster och sociala villkor - en rapport om konstnärer inom alla konstområden verksamma i Sverige 2014 utifrån kön, ålder, inkomst, näringsverksamhet, bosättning, utländsk bakgrund, utbildning och social bakgrund. Konstnärsnämnden

Kornberger, M., \& Brown, A. D. (2007). 'Ethics' as a discursive resource for identity work. Human Relations, 60(3), 497-518

Lund, A. (2009) "Men det är klart att det finns skit." Att gestalta könpå och av scenen. In i Edemo, Gunilla \& Engvoll, Ida (eds) Att gestalta kön. Berättelser om scenkonst, makt och medvetna val. Teaterhögskolan

Lund, A. (2013). Staging gender: The articulation of tacit gender dimensions in drama classes in a Swedish context. Gender and Education, 25(7), 907-922. https://doi.org/10.1080/09540253. 2013.860430
Lund, A. (2019). 'I feel sorry for them and I should do something, but I don't'. Spatial imaginaries and resistance to feminist change in the dramatic arts. Emotion, Space, and Society, 30, 27-33. https:// doi.org/10.1016/j.emospa.2018.12.003

Mangset, P., Kleppe, B., \& Røyseng, S. (2012). Artists in an iron cage? Artists' work in performing arts Institutions. The Journal of Arts Management, Law, and Society, 42(4), 156-175. https://doi.org/ 10.1080/10632921.2012.727773

Mark, E. (2016). Konstnärlig kvalitet med demokratiska perspektiv. Jämställdhetsintegrerad bedömning av ansökningar om bidrag och stipendier. Konstnärsnämndens skriftserie 2016.1. Konstnärsnämnden.

Miscevic, D. (2014). Bortom scenen: en sociologisk studie av frilansande skådespelares villkor. (p. 2014). Göteborgs universitet.

Muhr, S. L. (2008). Othering diversity-A Levinasian analysis of diversity management. International Journal of Management Concepts and Philosophy, 3(2), 176-189

Myndigheten för Kulturanalys. (2015). Kultur av vem? En undersökning av mångfald i den svenska kultursektorn, Rapport 2015:2. Myndigheten för Kulturanalys.

Parker, M. (2003). Introduction: Ethics, politics and organizing. Organization, 10(2), 187-203. https://doi.org/10.1177/13505 08403010002001

Pullen, A., \& Rhodes, C. (2014). Corporeal ethics and the politics of resistance in organizations. Organization, 21(6), 782-796

Pullen, A., \& Rhodes, C. (Eds.). (2015). The Routledge companion to ethics, politics and organizations. Routledge.

Randle, K., Leung, W. F., \& Kurian, J. (2007). Creating difference. University of Hertfordshire.

Robinson, R. K. (2007). Casting and caste-ing: Reconciling artistic freedom and antidiscrimination norms. California Law Review, 95(1), 1-73

Romani, L., Holck, L., \& Risberg, A. (2019). Benevolent discrimination: Explaining how human resources professionals can be blind to the harm of diversity initiatives. Organization, 26(3), 371-390

Schütz, A. (1964). Collected papers II: Studies in social theory. Martinus Nijhoff.

Scott, S. G., \& Lane, V. R. (2000). A stakeholder approach to organizational identity. The Academy of Management Review, 25(1), 43-62

Sigrid, R. (2008). Arts management and the autonomy of art. International Journal of Cultural Policy, 14(1), 37-48. https://doi.org/ $10.1080 / 10286630701856484$

Skillset. (2005). Survey of the audio visual industries' workforce 2005. Skillset.

Sol, S. L. (2019). The democratic value of participation in cultural policy. Comunicação e Sociedade, 36, 81-99. https://doi.org/10. 17231/comsoc.36(2019).2346

Statens offentliga utredningar (SOU) 2006: 42. Plats på scen. Betänkande av kommittén för jämställdhet inom scenkonstområdet. Sveriges riksdag

Tatli, A., \& Özbilgin, M. (2012). Surprising intersectionalities of inequality and privilege: The case of the arts and cultural sector. Equality, Diversity and Inclusion An International Journal, 31(3), 249-265

Thanki, A. \& Jeffreys S. (2006-07). Who are the Fairest? Ethnic segmentation in London's media production, Work Organisation. Labour and Globalisation, 1(1), 108-118.

Tyler, M. (2018). Reassembling difference? Rethinking inclusion through/as embodied ethics. Human Relations, 72(1), 48-68

Vestheim, G. (2009). The autonomy of culture and the arts-From the early bourgeois era to the late modern "Runaway world." In M. Pyykönen, N. Simanainen, \& S. Sokka (Eds.), What about cultural policy: Interdisciplinary perspectives on culture and politics. Minerva Kustannus. 
Zanoni, P., \& Janssens, M. (2007). Minority employees engaging with (diversity) management: An analysis of control, agency, and micro-emancipation. Journal of Management Studies, 44(8), $1467-6486$

Zanoni, P., Janssens, M., Benschop, Y., \& Nkomo, S. (2010). Unpacking diversity, grasping inequality. Rethinking difference through critical perspectives. Organization, 17(1), 9-29
Publisher's Note Springer Nature remains neutral with regard to jurisdictional claims in published maps and institutional affiliations. 